EMBRYARIDDLE
Aeronautical University

SCHOLARLY COMMONS
International Journal of Aviation, Aeronautics, and Aerospace

\title{
Base Pressure Control using Micro-jets in Supersonic Flow Regimes
}

Vigneshvaran Sethuraman

Monash University Malaysia, vigneshvaran.sethuraman@gmail.com

Sher Afghan Khan

International Islamic University Malaysia, sakhan@iium.edu.my

Follow this and additional works at: https://commons.erau.edu/ijaaa

Part of the Aerodynamics and Fluid Mechanics Commons

\section{Scholarly Commons Citation}

Sethuraman, V., \& Khan, S. (2018). Base Pressure Control using Micro-jets in Supersonic Flow Regimes. International Journal of Aviation, Aeronautics, and Aerospace, 5(1). https://doi.org/10.15394/ ijaaa.2018.1148

This Article is brought to you for free and open access by the Journals at Scholarly Commons. It has been accepted for inclusion in International Journal of Aviation, Aeronautics, and Aerospace by an authorized administrator of Scholarly Commons. For more information, please contact commons@erau.edu. 


\section{Base Pressure Control using Micro-jets in Supersonic Flow Regimes}

\section{Cover Page Footnote}

The authors express their sincere thanks to Prof K. Padmanaban, for his critical review and feedback on this paper. 


\section{Nomenclature}

AR Area ratio - Cross-sectional area of the enlarged duct to that of the of the nozzle exit

D Duct diameter

d Nozzle exit diameter

L Duct length

M Nozzle exit Mach number

L/D Length to Diameter ratio of the duct

$\mathrm{x} / \mathrm{D} \quad$ Axial pressure tap location along the duct length

$P_{a} \quad$ Atmospheric pressure

$P_{b} \quad$ Base pressure

$P_{w} \quad$ Wall pressure

$P_{c} \quad$ Control pressure

$P_{01} \quad$ Stagnation pressure in the settling chamber

$P_{02} \quad$ Stagnation pressure in the blowing settling chamber

$P_{a} \quad$ Pressure at nozzle exit

$u_{P_{a}} \quad$ Uncertainty in atmospheric pressure

$u_{P_{0}} \quad$ Uncertainty in settling chamber pressure

$u_{P_{c}} \quad$ Uncertainty in control chamber pressure

$u_{P_{b}} \quad$ Uncertainty in base pressure

CE Correctly expanded

U Under-expanded

O Over-expanded

WC With control mechanism

WO Without control mechanism

\section{Introduction}

Fuel efficiency is key to effective performance of airplanes, rockets and missiles. The factors that restrict the vehicle performance are excessive air friction on the outer body of vehicles, namely drag, and poor air-fuel mixing in the engine. Airflow plays a dominant role in determining the performance levels and, when controlled, can lead to improved efficiency. The rear portion of vehicles is the base region. Air undergoes a sudden expansion at the base region as there is an area of larger cross-section downstream of the base for the flow to expand, resulting in development of a low-pressure recirculation region near the base. The base pressure is considerably lesser than the free stream atmospheric pressure. The reason for the pressure at the base region to be lesser than the atmospheric pressure is due to the 
suction vacuum happening in the region, when the flow exits from the nozzle and reattaches on the duct. The pressure along that duct cannot exceed $1 \mathrm{kPa}$, as the duct is axi-symmetric. Drag occurring in the base region is termed as base drag, and can constitute up to $50 \%$ to $60 \%$ of the total drag at transonic flow regime, and the base drag contribution is seen to reduce at high supersonic flow to about $30 \%$. In the combustion chamber of certain engines there exists a sudden expansion region where mixing of air and fuel occurs. Poor mixing would lead to higher fuel consumption, resulting in increased operational costs. Air pressure at the base region or base pressure is the pertinent parameter which needs to be controlled to obtain improved performance and is the foundation for this research work.

In the case of internal flows, jet expansion in sudden expansion flows governs mixing efficiencies. Base pressure when decreased, is well suited for applications where there is a need for flow-mixing enhancement such as in combustion chambers of jet engines, while with an increase in base pressure, base drag can be reduced in external flow conditions over rockets and missiles etc. Despite both the phenomenon being different, it however leads to one final output: improved efficiency.

\section{Theoretical Framework}

Axi-symmetric sudden expansion phenomenon can be characterized by separation, recirculation and reattachment of flow. The flow field is segmented by a shear layer into two main regions, namely the recirculation region and main flow region. The point at which the dividing streamline strikes the wall is called reattachment point (Sethuraman, Vigneshvaran et al., 2016).

The reattachment of a turbulent shear layer is an important phenomenon in suddenly expanded flows as flow reattachment plays a vital role. The backwardfacing step is the simplest reattaching flow concept. The separation line is straight and fixed at the edge of the step, and there is only one separated zone. The streamlines are nearly parallel to the wall at the separation point, so significant upstream influence occurs only downstream of the flow separation. The backwardfacing step, though being simple has a very complex flow field, which is shown in Figure 1 (Eaton, J. K. et. al., 1981). Large scale vortices are formed in the recirculation zone.

The Nozzle Pressure Ratio (NPR) is the ratio of stagnation pressure in the settling chamber, to the pressure of the environment to which the jet is discharged. The NPR dictates level of flow expansion at the exit of the nozzle. The static pressure at the nozzle exit, when lower than the pressure of the environment, the jet 
is termed as over-expanded $(\mathrm{O})$. In the case when the exit pressure is equal to the environmental pressure, the jet is said to be correctly expanded (CE) and if the exit pressure is greater than the environmental pressure, jet is termed as under-expanded (U). In the cases of under-expanded and correctly expanded flows, there is expansion fan and oblique shocks at the nozzle throat, respectively.

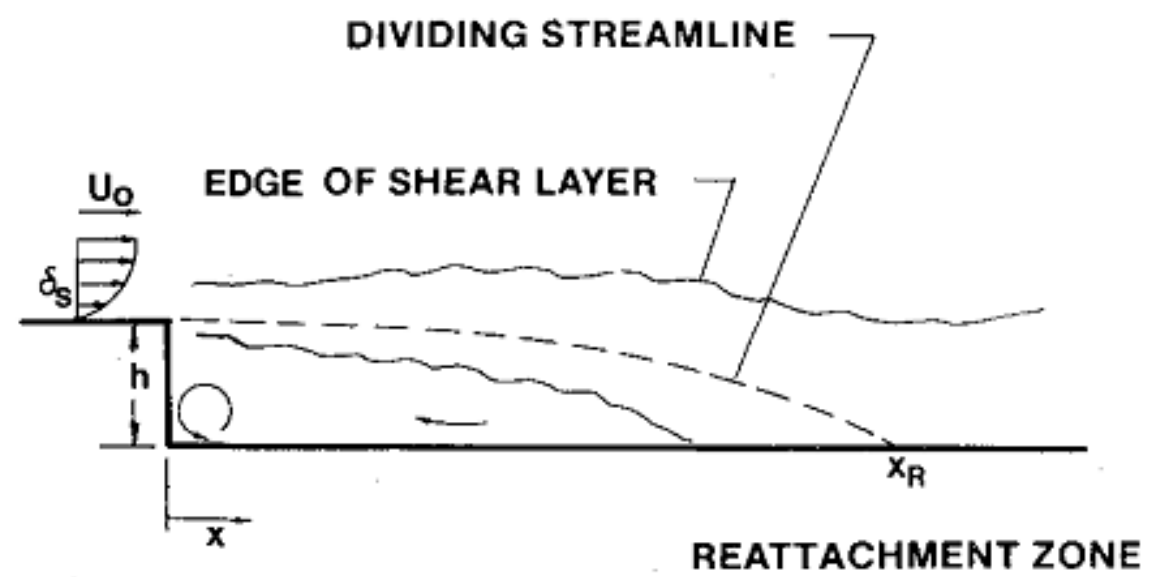

Figure 1. Backward-facing step flow field (Eaton, J. K. et. al., 1981)

The boundary layer type and thickness upstream of sudden expansion is related to the pressure in the base region, as observed by Wick for sonic flow condition (Wick, Robert S., 1953). In another study by Wick (Wick, Robert S., 1955), a rectangular duct with sudden expansion region was tested and hence, base pressure could be measured at two corners as the duct was two dimensional with constant length and width. The measurement in two corners was made because the corners are not interconnected. There was a possibility of having a non-symmetrical condition if the pressure downstream of the expansion was raised high enough relative to the pressure at the exit of the nozzle.

The corners are important for base pressure measurement as the flow downstream of expansion gets re-circulated in the corner regions, where vortex dynamics plays a vital role. The intensity of the vortex generated in the corner determines the intensity of base pressure are in agreement with the measurements of Korst (Korst, H.H., 1954) for similar geometry. This work emphasizes the importance of corners in base pressure measurements. 


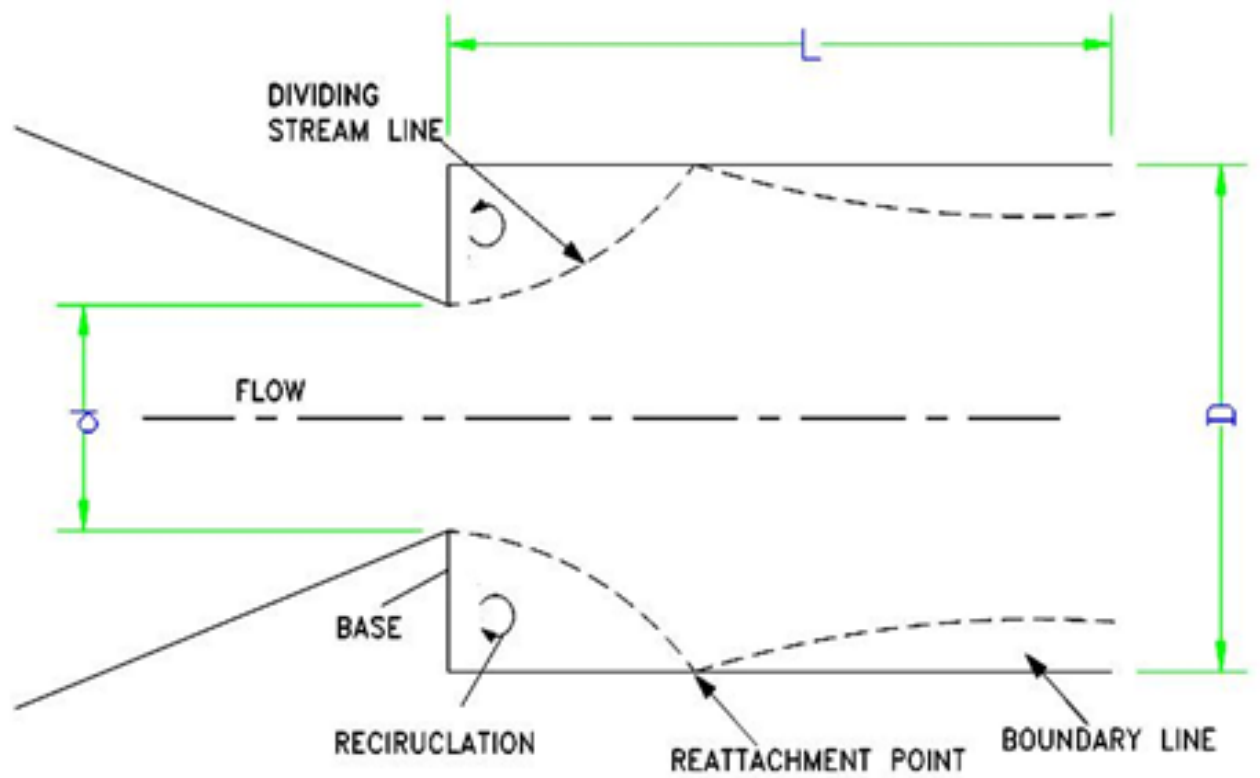

Figure 2. Schematic diagram of sudden expansion phenomenon

The effect of base pressure by sudden expansion of air in a cylindrical duct was studied by Williams and Anderson. The base pressure resulting from the abrupt expansion of an air jet from a circular nozzle into a concentric cylindrical duct or shroud was measured. Stagnation pressure is the pressure at the stagnation point on the body where, theoretically, the velocity of fluid flow is zero and there is no viscosity present. The flow attachment, separation and reattachment were examined and visualized in the shroud wall, and a loss is exhibited by the pressure at the base of the shroud acting like a supersonic parallel diffuser. Stagnation pressure ratios of the forcing jet of up to six atmospherics were used, with shrouds of various lengths and diameters. As the primary or forcing jet pressure is increased and then decreased, the jet flow attaches and separates from the shroud wall and a hysteresis effect is exhibited by the pressure at the base of the shroud. With an attached flow, the base pressure attains a minimum value which depends mainly on the duct-tonozzle-area ratio and on the geometry of the nozzle, lower base pressures being obtained with convergent-divergent nozzles. When the jet pressure was increased beyond that required to attain the minimum value of the base pressure, it was observed that the ratio of the forcing jet pressure to base pressure remained constant (Williams, T. J. and Anderson, J. S., 1968).

Base pressure plays a very dominant role in the case of flow mixing of jets as well as base drag. The controlling of base pressure can lead to improved performance. When base pressure is decreased, it is well suited for applications where there is a need for flow-mixing enhancements such as in combustion 
chambers, while with an increase in base pressure, base drag can be reduced for applications such as rockets, shells, Air-craft Bombs, and missiles. This research focuses on enhancing base pressure, leading to reduction in base drag.

The control strategies are broadly classified into two types, (a) active control and (b) passive control. Significant amount of literature is available for each of the above-mentioned control strategies. Passive controls are minor geometrical modifications to duct such as cavities and ribs which vary the jet control to change the shear layer stability characteristics, while active controls require an external source of power to perform their role as control devices.

Micro-jets are an active flow control mechanism employed to assist in controlling pressure at the base region. Usually, active control mechanisms require additional support/equipment to perform their role as flow control. This requirement is eliminated in the case of micro-jets as they are simple protrusions on the nozzle exit periphery with air being supplied from the blowing settling chamber $\left(\mathrm{P}_{0 \mathrm{c}}\right)$ connected to the main settling chamber. Passive/Active control mechanisms also assist in breaking down the large-scale vortices in the reattachment region to small scale vortices, making them better transporters of mass and momentum. (Sethuraman, Vigneshvaran et al., 2016). Micro-jets are also capable of breaking down vortices.

Khan and Rathakrishnan (Khan, Sher Afghan and Rathakrishnan, E., 2002, 2003, 2004, 2006) studied sudden expansion phenomenon for under-expanded, over-expanded and correctly expanded supersonic flow conditions. The flow control was by micro-jets. It was found that micro-jets were effective for the underexpanded flow condition and the rise in base pressure values was as high as $90 \%$. The nozzle pressure ratio has a definite role to play in fixing the level of base pressure with and without flow control for supersonic flow conditions (Baig, M. Ahmed Ali et al., 2011).

It is clear that micro-jets are capable of improving base pressure at different area ratios and for flow and geometrical parameters such as nozzle pressure ratios (NPRs) and length-to-diameter (L/D) ratios. The variation of reattachment point with and without micro-jets are explained in the results and discussion section of this paper. However, in this work a comparison of the different cases of the flow has not been compiled and a quantitative study is also lacking in the field of sudden expansion with active flow control.

This research aims to study the effect of active flow control at supersonic flow conditions using active control devices in annular pipes. The active control 
devices used in this work are micro-jets, which are simple protrusions on the nozzle exit periphery with air being supplied from the blowing settling chamber $\left(\mathrm{P}_{0 c}\right)$ connected to the settling chamber. The percentage increase in base pressure for different conditions with respect to area ratio is a significant contribution of this study as it is expected to provide an idea of how base pressure value is set to change with increase in area ratio, Mach number, L/D ratio, and nozzle pressure ratio. Wall pressure measurements were made to understand the quality of the flow field in the duct and the impact of micro jets varying the reattachment points and the cases for which they were beneficial and not beneficial.

\section{Experimental Setup}

The sudden expansion phenomenon in this research is achieved with an enlarged pipe section attached past the nozzle exit. Major emphasis was on measuring pressure at the base region $\left(\mathrm{P}_{\mathrm{b}}\right)$ and the effect of micro jets at the base region. Micro jets are an active flow control mechanism employed to assist in controlling pressure at the base region. Usually, active control mechanisms require additional support/equipment to perform their role as flow control. This requirement is eliminated in the case of micro-jets as they are simple protrusions on the nozzle exit periphery with air being supplied from the blowing settling chamber $\left(\mathrm{P}_{0 c}\right)$ connected to the main settling chamber. The settling chamber pressure $\left(\mathrm{P}_{01}\right)$, is higher compared to $\left(\mathrm{P}_{0 c}\right)$ due to frictional losses that possibly occur during the air flow. There are four protrusions (marked ' $c$ ') for micro-jets and four more (marked ' $m$ ') for measuring base pressure.

The experimental setup basically consists of a two-stage reciprocating compressor, capable of delivering $0.17 \mathrm{~m}^{3} / \mathrm{s}$ connected to three air receiver tanks with a storage capacity of $84.85 \mathrm{~m}^{3}$. $0.051 \mathrm{~m}$ diameter circular pipelines are used to connect to the settling chamber, and by the nozzle assembly and the pipe section. A diaphragm type back pressure valve operated by pressure relief pilot valve permits the dryer to operate at $3447.38 \mathrm{kPa}$, while the pressure in the storage tank builds up from atmospheric to storage pressure. Detailed schematic of the setup is shown in Figure 3. A blowing settling chamber is connected to the main settling chamber, and it provides air supply to the micro-jets located at the periphery of the nozzle exit. 


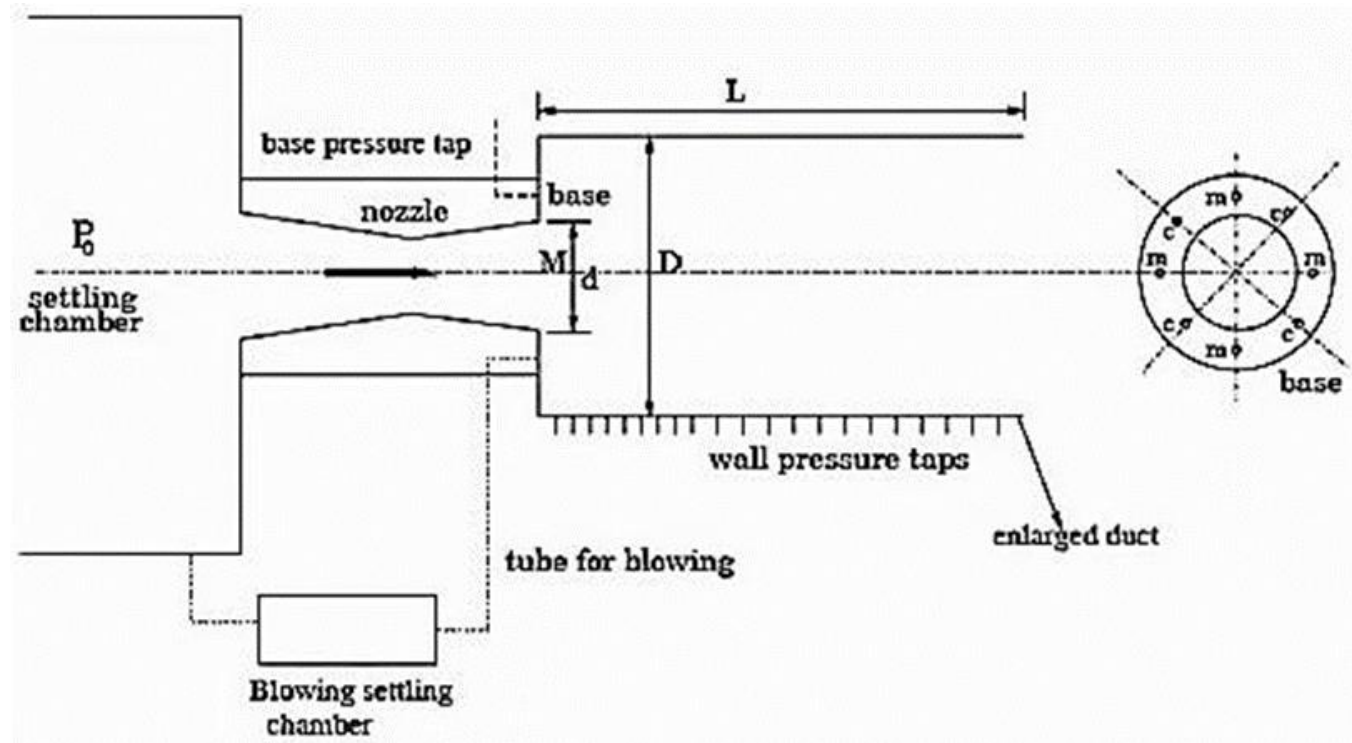

Figure 3. Experimental setup

The 9000 Series Intelligent Pressure Scanners - Model 9010, interfaced with a PC386, was used for measuring pressure at the base and stagnation pressure in the settling chamber as well as pressure in the blowing settling chamber. It has 16 channels and the pressure range is up to $2 \mathrm{MPa}(0-20$ atmosphere). It averages 250 samples per second and displays the reading. The software provided by the manufacturer was used to interface the transducer with the computer. 6 pressure tapings were used for data acquisition of base pressure data and the stagnation pressure in the main settling chamber and the control chamber, while the remaining 10 acquired wall pressure data. Experiments were repeated to measure wall pressure data, due to limited channels available for measurements.

\section{Results and Discussion}

Experiments were conducted for area ratios of 2.56, 3.24, 4.84 and 6.25 at Mach numbers 1.25, 1.3, 1.48, 1.6, 1.8, 2.0, 2.5 and 3.0 \& for L/D ratios of 1, 2, 3, 4, 5, 6, 8, and 10. The flow conditions were maintained at NPR 3, 5, 7, 9, 11, correctly expanded, under-expanded and over-expanded. Major emphasis was on understanding the trend of base pressure and wall pressure measurements for the varied area ratios at a fixed L/D ratio of 10 . However, this paper solely focuses on the case of L/D 10 as it was found that this L/D ratio provides an overview of the trend distribution for other lower $\mathrm{L} / \mathrm{D}$ values.

The data presented in this paper are for two typical Mach numbers of 1.25 and 2 while the conclusions drawn in this paper holds good for the cases of low 
supersonic flows and moderately high supersonic flows. Micro-jets are used as the active control mechanism for flow control, which in turn was expected to alter the base pressure characteristics. The results are presented for data without control mechanism and with control. The comparative study not only provides variation or similarity in base pressure values for a certain area ratio and $\mathrm{L} / \mathrm{D}$ condition but assists in ascertaining the percentage change in base pressure values at flow conditions of correct expansion (CE), under-expansion (U) and over-expansion (O). The NPR values for Mach 1.25 and Mach 2 at CE are NPR 2.59 and NPR 7.83 respectively. In the case of U, it is NPR 3.89 for Mach 1.25 and NPR 11.85 for Mach 2, while for $\mathrm{O}$ it is NPR 2.13 for Mach 2. The NPR values were obtained using isentropic relations,

$$
\frac{P_{01}}{P_{1}}=\left(1+\frac{\gamma-1}{2} M^{2}\right)^{\gamma /(\gamma-1)}
$$

The under-expansion phenomenon is such that the pressure at the exit is higher than the ambient pressure at the nozzle exit. As the flow expands, expansion fans are generated at the nozzle exit followed by weak diamond-shaped shocks which weaken downstream of the flow, as in the case of free jets. Over-expansion phenomenon is a scenario wherein the pressure ratio $\left(\mathrm{P}_{\mathrm{e}} / \mathrm{P}_{\mathrm{a}}\right)$ is less than 1 , which means the pressure post nozzle exit is much lesser than the ambient pressure and hence there will be oblique shock at the nozzle exit.

The plots of base pressure variation for different area ratios at $\mathrm{CE}$ and $\mathrm{U}$ conditions for Mach 1.25 and similar conditions for Mach 2, along with those for over-expansion, have been presented. The percentage increase in base pressure is also presented for both cases. It can be inferred from Figure 4 that for the case of Mach 1.25, the control mechanism (WC) has no effect in controlling the base pressure and the trend seems to overlap that of the case without flow control (WO).

In the case of $\mathrm{CE}$, the base pressure values are very close to each other and the lines seem to be coinciding, and the pressure at the nozzle exit equals the ambient pressure at the exit of the enlarged pipe. The suction happening at the base region, gradually reduces with increase in area ratio. This may be due to the fact that a larger dead-air region is available before the shear layer originating from the nozzle exit and reattaches on the wall of the pipe section and the will progressively. This enables the base pressure value to gradually increase with increase in area ratio due to the increase in the reattachment length with the increase in relief to the flow.

Control mechanism has a very mild effect on base pressure, which is approximately $4.5 \%$ and $3.97 \%$ higher than the case of flow without control in the 
under-expanded state for the area ratios 2.56 and 3.24 respectively. Micro-jets, which are positioned close to the exit of the nozzle, try to decrease the suction occurring at the base region in under-expansion condition for the Mach 1.25 inlet condition. This leads to increase in base pressure. With increase in area ratio, percentage increase in base pressure gradually reduces. The values for underexpansion are reasonably lower compared to the case of CE. The pressure at the exit is higher than the ambient and hence could result in lower recirculation at the base, leading to lower base pressure values. For higher area ratios such as 4.84 and 6.25 the base pressure values seem to overlap each other, which emphasizes the fact that for higher area ratios the effect of control mechanism diminishes.

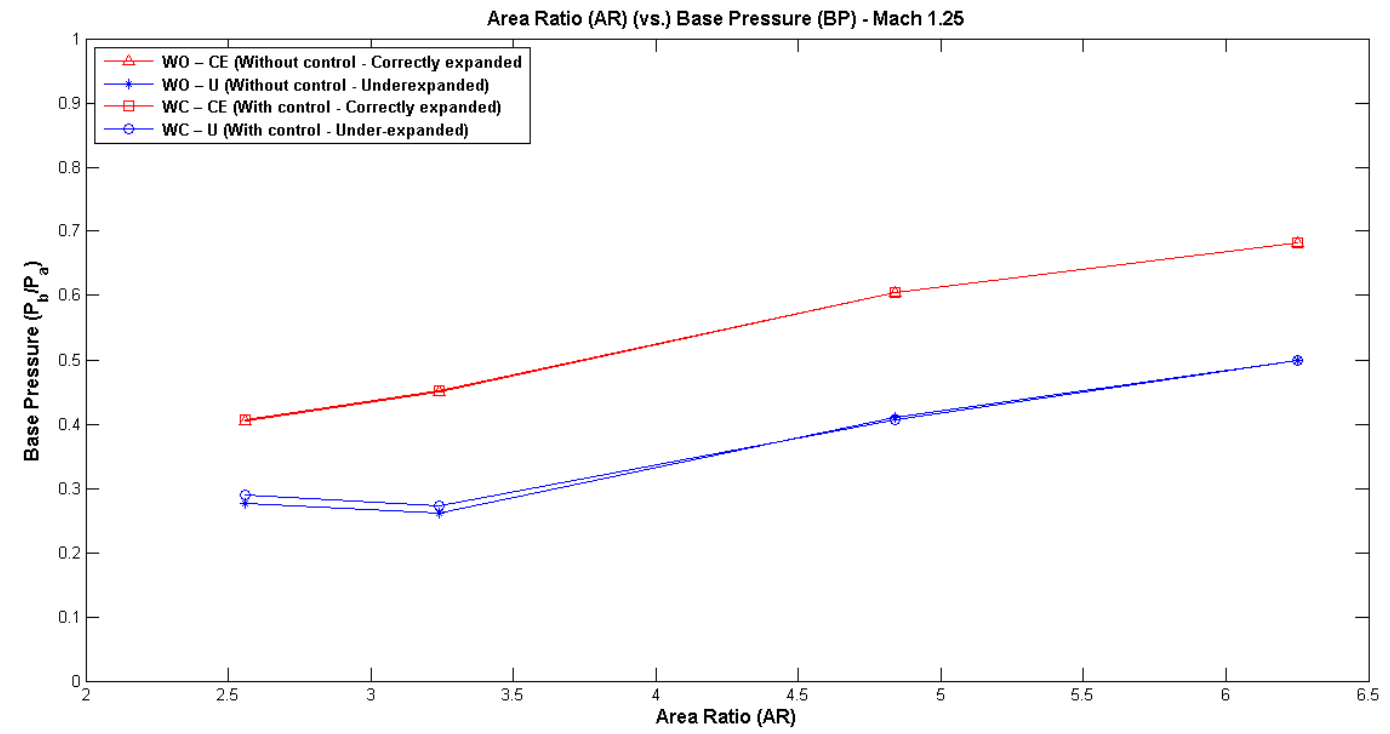

Figure 4. Area Ratio (AR) (vs.) Base Pressure $\left(\mathrm{P}_{\mathrm{b}} / \mathrm{P}_{\mathrm{a}}\right)-$ Mach 1.25

Table 1

Quantitative data for Area Ratio (AR) (vs.) Non-dimensional Base Pressure $\left(P_{b} / P_{a}\right)-$ Mach 1.25

\begin{tabular}{|c|c|c|c|c|}
\hline AR & WO - CE & WO - U & WC - CE & WC - U \\
\hline 2.56 & 0.4038 & 0.276 & 0.4069 & 0.289 \\
\hline 3.24 & 0.4497 & 0.2612 & 0.4514 & 0.272 \\
\hline 4.84 & 0.6042 & 0.4112 & 0.6046 & 0.4067 \\
\hline 6.25 & 0.6829 & 0.4984 & 0.683 & 0.4991 \\
\hline
\end{tabular}

The difference in base pressure values for the cases with and without flow control is presented as percentages to understand the increase in base pressure with use of flow control in Figure 5. It can be seen that there is very minimal effect of control mechanism on base pressure for Mach 1.25 CE condition. For the under- 
expanded condition, the increase in base pressure is about $4.5 \%$ for AR 2.56 and $3.97 \%$ for AR 3.24. In the under-expanded state, as the AR increases the dead-air region becomes weaker, and with low supersonic condition the recirculation is expected to be reduced as the dead-air region is quite large at higher ARs.

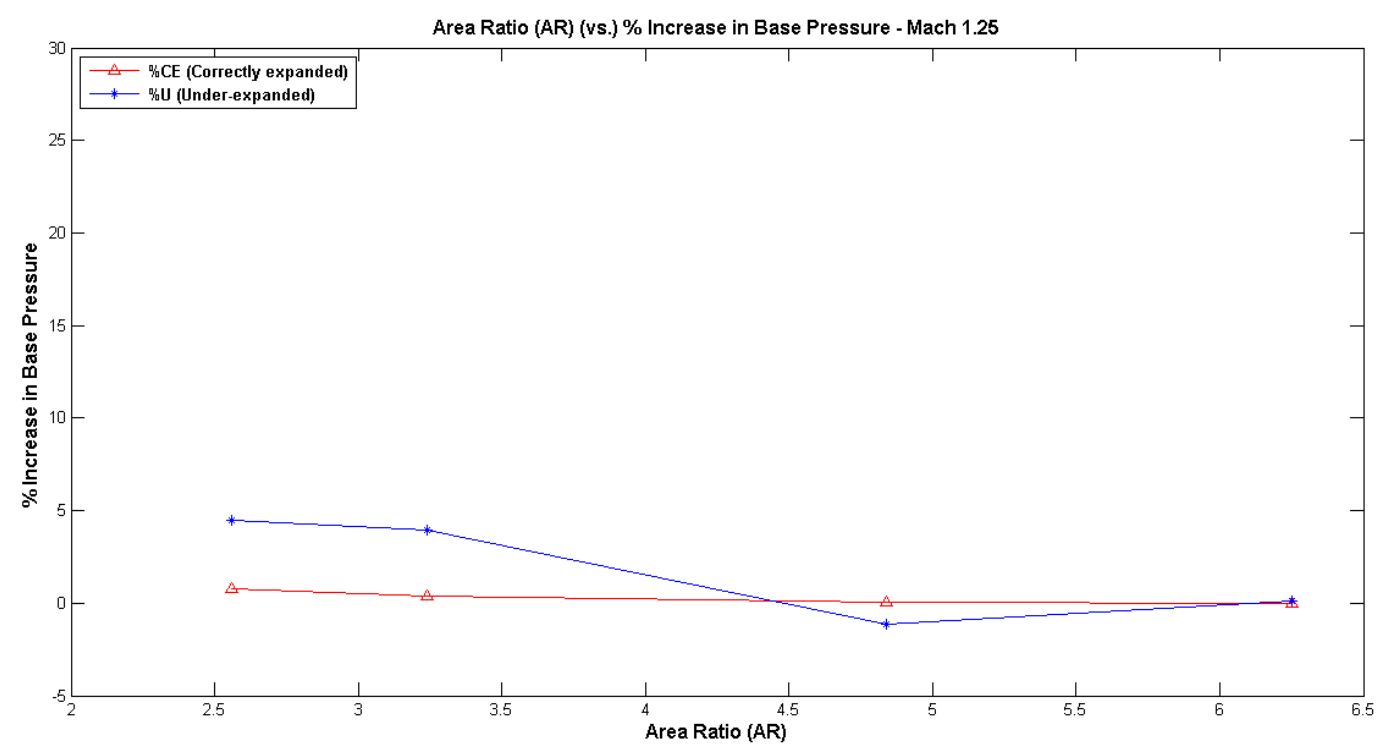

Figure 5. Area Ratio (AR) (vs.) \% Increase in Base Pressure - Mach 1.25

Table 2

Quantitative data for Area Ratio (AR) (vs.) \% Increase in Base Pressure - Mach 1.25

\begin{tabular}{|c|c|c|c|c|}
\hline AR & CE & U & \% CE & \%U \\
\hline 2.56 & 0.0031 & 0.013 & 0.768 & 4.498 \\
\hline 3.24 & 0.0017 & 0.0108 & 0.378 & 3.971 \\
\hline 4.84 & 0.0004 & -0.0045 & 0.066 & -1.106 \\
\hline 6.25 & 0.0001 & 0.0007 & 0.015 & 0.140 \\
\hline
\end{tabular}

It can be seen from Figure 5 that the change in base pressure value for AR4.84 becomes negative. For AR 6.25, the base pressure value becomes almost zero. It can be concluded that control mechanism is effective only for lower area ratios in under-expanded low supersonic conditions as in the case of Mach 1.25. The reason for this trend could be at lower area ratios the reattachment length is small as compared to higher area ratio, also for large area ratio already base pressure assumes higher at the nozzle exit itself, since inertia level is same under these circumstances when control mechanism is activated it does not influence the base pressure as compared to higher area ratio for under expanded jet. In case of correctly expanded nozzle flows Mach waves/weak waves will be positioned at 
nozzle exit and their intersection and reflections will continue, in view of the presence of these waves the control mechanism in the form of micro jet will not be effective.

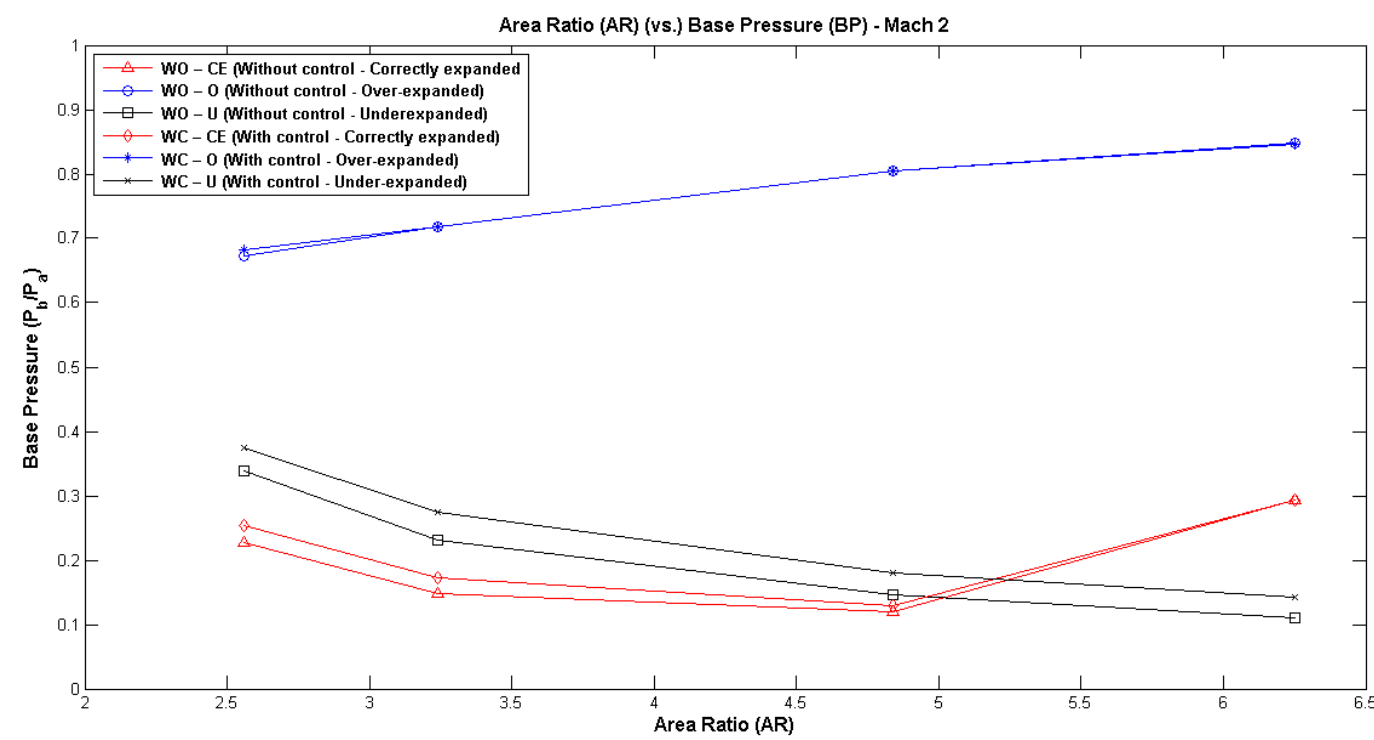

Figure 6. Area Ratio (AR) (vs.) Base Pressure $\left(\mathrm{P}_{\mathrm{b}} / \mathrm{P}_{\mathrm{a}}\right)-$ Mach 2

Table 3

Quantitative data for Area Ratio (AR) (vs.) Non-dimensional Base Pressure $\left(P_{b} / P_{a}\right)-$ Mach 2

\begin{tabular}{|c|c|c|c|c|c|c|}
\hline AR & WO - CE & WO - O & WO - U & WC - CE & WC - O & WC - U \\
\hline 2.56 & 0.227 & 0.6723 & 0.338 & 0.254 & 0.682 & 0.375 \\
\hline 3.24 & 0.1483 & 0.7172 & 0.2311 & 0.1729 & 0.7171 & 0.2746 \\
\hline 4.84 & 0.1207 & 0.8041 & 0.1467 & 0.1298 & 0.804 & 0.181 \\
\hline 6.25 & 0.294 & 0.8486 & 0.111 & 0.294 & 0.8462 & 0.142 \\
\hline
\end{tabular}

For the flow condition of Mach 2, the over-expanded flow condition was additionally maintained, as compared to that of Mach 1.25. It is interesting to note that as Mach number increases from 1.25 to 2, at CE there is a drop in base pressure values with and without control mechanism up to AR 4.84 and then there is a sudden rise in value in the case of AR 6.25. This could possibly be due to the fact that the step height for AR 2.56 to 4.84 gradually enabled suction to increase at the base, which in turn forced the base pressure to reduce. In the case of AR 6.25, the step height has exceeded its limit to such an extent that the re-circulation region possibly loses its ability to control the suction levels, as with previous area ratios. In the dead-air region/re-circulation zone, the strength of the vortices assists in reducing base pressure along with the flow condition $\left(\mathrm{P}_{\mathrm{e}} / \mathrm{P}_{\mathrm{a}}\right)$. For $\mathrm{CE}$, the $\mathrm{P}_{\mathrm{e}} / \mathrm{P}_{\mathrm{a}}=1$, 
that is, the ratio of nozzle exit pressure and ambient pressure equals 1 . In such a condition AR 4.84 seems to have the least base pressure value of 0.1207 without flow control, as compared to that of other area ratios as well as for AR 4.84 with flow control.

The percentage increase in base pressure (Figure 6) for the ARs 2.56 and 3.24 is $11.894 \%$ and $16.588 \%$ respectively. For AR 4.84 and 6.25, the effect of Micro-jets is poor in controlling the flow and hence there is a drop-in percentage. At AR 6.25, the percentage change is nil, which corresponds to the fact that flow control loses it effect completely at very high area ratios in the case of correctly expanded flows.

Over-expansion creates room for a strong reverse flow to occur from the pipe exit to the nozzle exit, leading to very low suction at the base (Figure 6). Another point that can be inferred is that, as the step-height increases the base pressure steadily increases, which is clearly due to over-expansion. Added to that, shock waves get generated in over-expansion condition and reflected from wall-towall leading to a very weak re-circulation region zone. The effect of flow control is totally insignificant in the over-expansion flows, attributed to the reasons mentioned above.

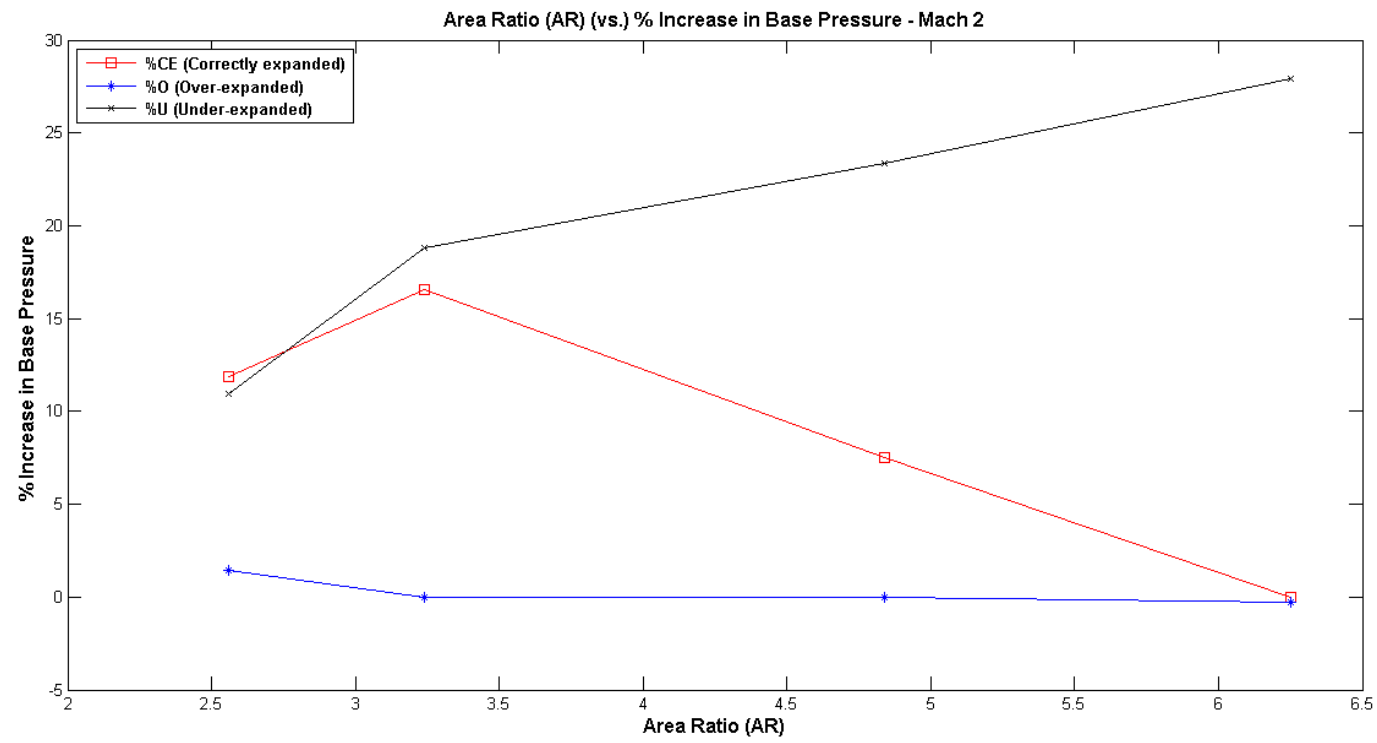

Figure 7. Area Ratio (AR) (vs.) \% Increase in Base Pressure - Mach 2

The percentage increase in base pressure (Figure 7) for the ARs 2.56 and 3.24 is $11.894 \%$ and $16.588 \%$ respectively. For AR 4.84 and 6.25, the effect of Micro-jets is poor in controlling the flow and hence there is a drop-in percentage. 
At AR 6.25, the percentage change is nil, which corresponds to the fact that flow control loses it effect completely at very high area ratios in the case of correctly expanded flows.

Table 4

Quantitative data for Area Ratio (AR) (vs.) \% Increase in Base Pressure - Mach 2

\begin{tabular}{|c|c|c|c|c|c|c|}
\hline AR & WO - CE & WO - O & WO - U & WC - CE & WC - O & WC - U \\
\hline 2.56 & 0.227 & 0.6723 & 0.338 & 0.254 & 0.682 & 0.375 \\
\hline 3.24 & 0.1483 & 0.7172 & 0.2311 & 0.1729 & 0.7171 & 0.2746 \\
\hline 4.84 & 0.1207 & 0.8041 & 0.1467 & 0.1298 & 0.804 & 0.181 \\
\hline 6.25 & 0.294 & 0.8486 & 0.111 & 0.294 & 0.8462 & 0.142 \\
\hline
\end{tabular}

In contrast, there is a sharp decline in base pressure with increase in area ratio in the case of under-expansion. It is applicable for both cases that use and do not use flow control. A distinct difference in base pressure values is seen in underexpansion condition, with increase in base pressure ranging approximately between $11 \%$ to $28 \%$ for AR 2.56 to 6.25 (Figure 7). The distinction is that the micro-jets play an active role in supersonic flow conditions such as Mach 2, as compared to low Mach numbers such as Mach 1.25. Hence, it can be concluded that micro jets are of use in boosting base pressure only at higher Mach numbers at underexpanded conditions.

In case of under expanded jets $\left(\mathrm{P}_{\mathrm{e}} / \mathrm{P}_{\mathrm{a}}>1\right)$, there will be expansion fan at the nozzle exit, followed by intersection of the waves in the duct, reflection of the waves from the duct wall, recombination waves, formation of diamond shock, as well as the barrel shock that makes flow field very complex. Under these circumstances when the micro jets are activated they are unable to influence the flow field for the lower area ratio, however, the control is able to influence the flow field in the dead region and as high as $28 \%$ increase in the base pressure is achieved for the highest area ratio of the present study.

\section{Wall Pressure and the Flow Development in the Duct}

One of the major problems faced, whenever controls are introduced in a sudden expansion flow field is that the pressure field in the duct becomes oscillatory in the base region. In other words when a control mechanism is introduced to control the base pressure, there is a possibility that it might adversely affect the nature of the flow field in the duct. To study this undesirable effect and its impact on flow reattachment, the wall pressure distribution in the duct was measured. For the case of Mach 1.25, as area ratio increases, the reattachment point gets closer to the nozzle exit. The phenomenon is common for both under-expanded and 
correctly-expanded cases. It can be learnt that micro-jets do not have a significant impact on the reattachment point in the case of low-supersonic flows, such as in the case of Mach 1.25 (Figure 8). The expansion fan generated post the nozzle exit, is clearly visible in the case of area ratio 2.56, under-expansion condition (Figure 9). This could be attributed to the fact that the step height available in the case of area ratio 2.56 is ideal for the flow to expand at Mach 1.25. For higher area ratios, the expansion fan starts dampening from L/D 3.5 onwards and this is due to heavy impact of back pressure from the pipe exit. The flow starts to reach atmospheric pressure upon dampening.

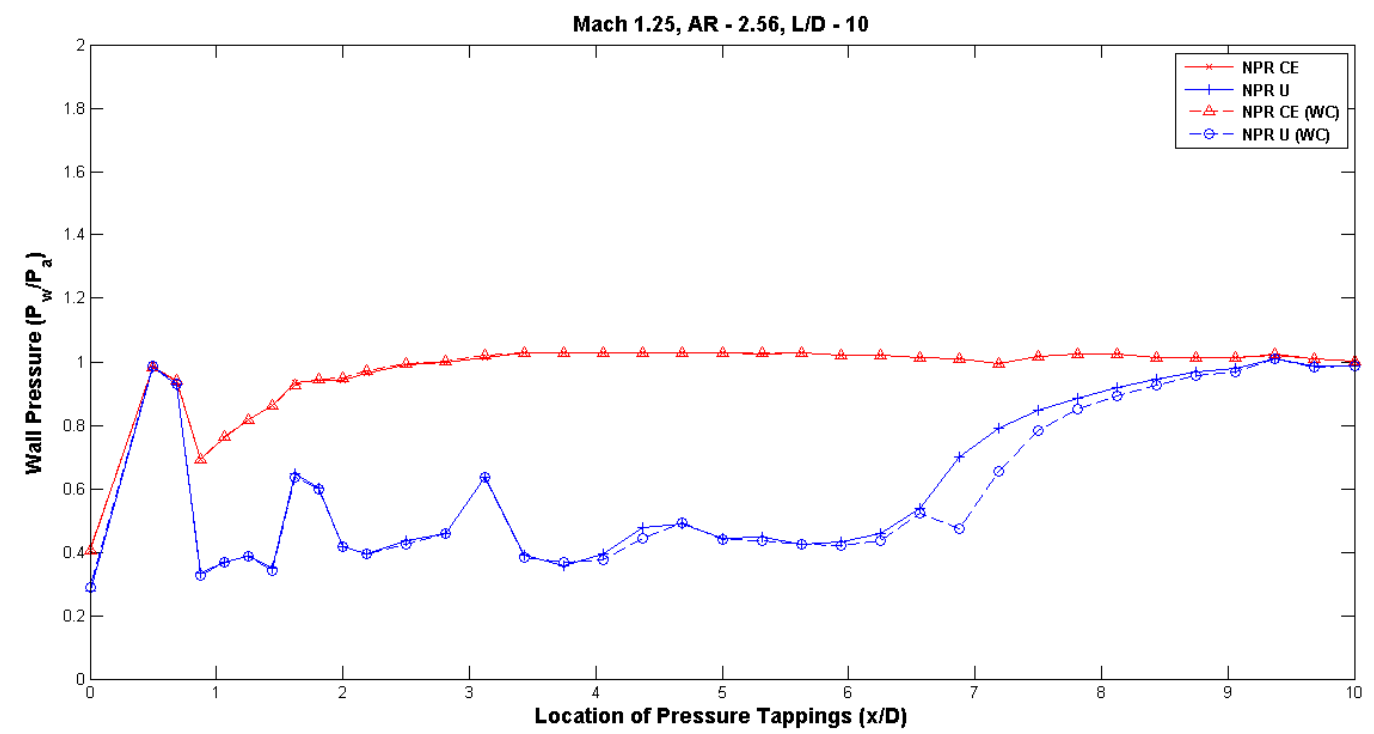

Figure 8. Wall Pressure $\left(\mathrm{P}_{\mathrm{w}} / \mathrm{P}_{\mathrm{a}}\right)$ (vs.) Location of Pressure Tapping (x/D) - Mach 1.25, AR - 2.56, $\mathrm{L} / \mathrm{D}-10$

Wall pressure in the duct for Mach 1.25 for area ratio 2.56 at $\mathrm{L} / \mathrm{D}=10$ is presented in Figure 8 . In case of correctly expanded case $x / D=1$ seems to be the reattachment length as there is progressive recovery in the wall pressure and within $\mathrm{x} / \mathrm{D}=2$ the wall pressure ratio $\left(\mathrm{P}_{\mathrm{w}} / \mathrm{P}_{\mathrm{a}}\right)$ has reached nearly equal to one. In case of under expanded jets due to the presence of waves and its reflection, the flow field is oscillatory till $\mathrm{x} / \mathrm{D}=3.5$ and then there is smooth recovery of the wall pressure. But from $x / D=6$ onwards control results in decrease of wall pressure. However, the flow filed in the duct with and without control remains the same. Hence, we can say that the control in the form of micro jets does not adversely affect the flow field.

Figure 9 presents the wall pressure distribution for area ratio 3.24 for Mach 1.25 at $\mathrm{L} / \mathrm{D}=10$, for this increased area ratio the reattachment point lies within $\mathrm{x} / \mathrm{D}$ $=1$. For correctly expanded as well as under expanded case, due to the presence of 
the Mach waves and expansion waves there is smooth recovery of wall pressure. Flow field with and without control remains the same.

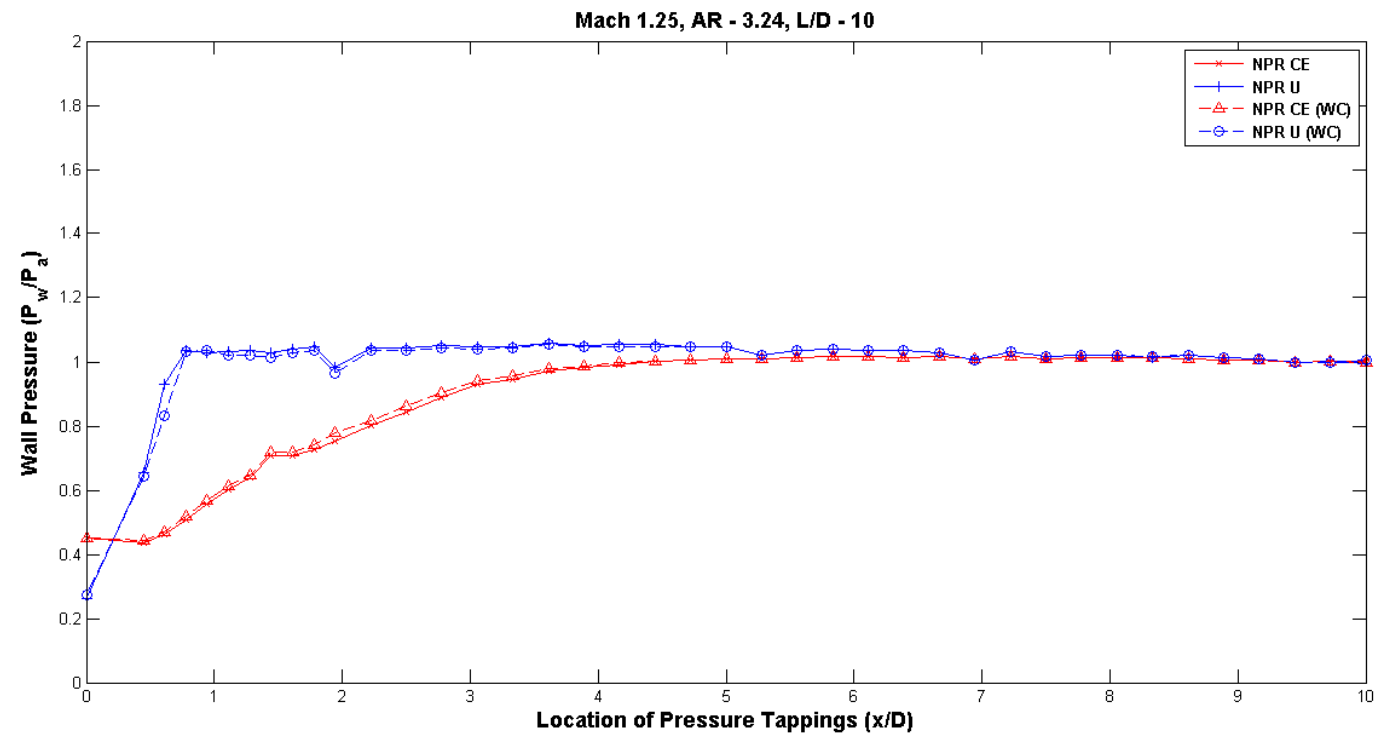

Figure 9. Wall Pressure $\left(\mathrm{P}_{\mathrm{w}} / \mathrm{P}_{\mathrm{a}}\right)$ (vs.) Location of Pressure Tapping (x/D) - Mach 1.25, AR - 3.24, $\mathrm{L} / \mathrm{D}-10$

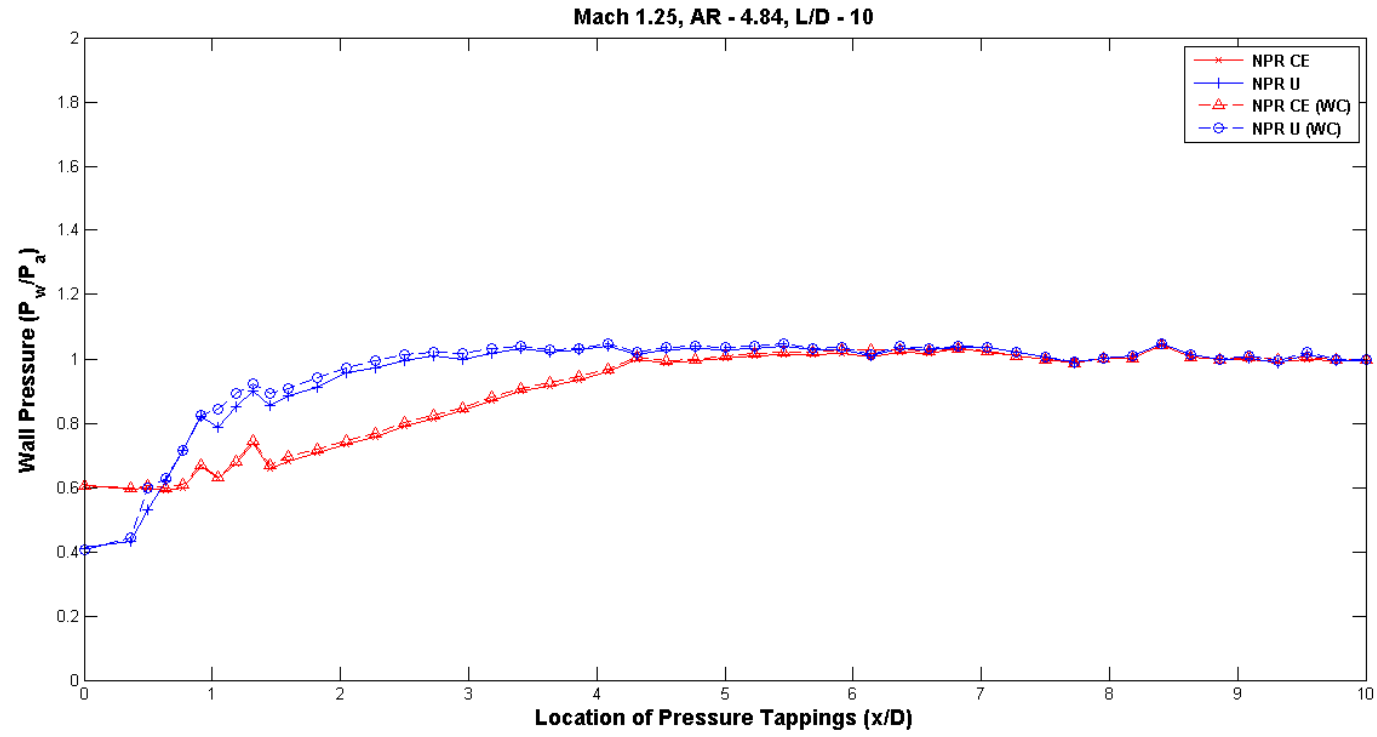

Figure 10. Wall Pressure $\left(\mathrm{P}_{\mathrm{w}} / \mathrm{P}_{\mathrm{a}}\right)$ (vs.) Location of Pressure Tapping (x/D) - Mach 1.25, AR 4.84, $\mathrm{L} / \mathrm{D}-10$

Figures 10 and 11 show wall pressure distribution for area ratio 4.84 and 6.25 , the effect of higher area ratio is clearly seen, in Figures 8 and 9, the initial 
wall pressure values $\left(\mathrm{P}_{\mathrm{w}} / \mathrm{P}_{\mathrm{a}}\right)$ which were in the range from 0.3 to 0.4 for lower area ratio (2.56 and 3.24) has enhanced in the range (0.42 to 0.6$)$ and (0.5 to 0.7$)$ for area ratios 4.84 and 6.25 . There smooth recovery of the wall pressure in both the ducts of higher area ratios. Also, the flow field is unaltered.

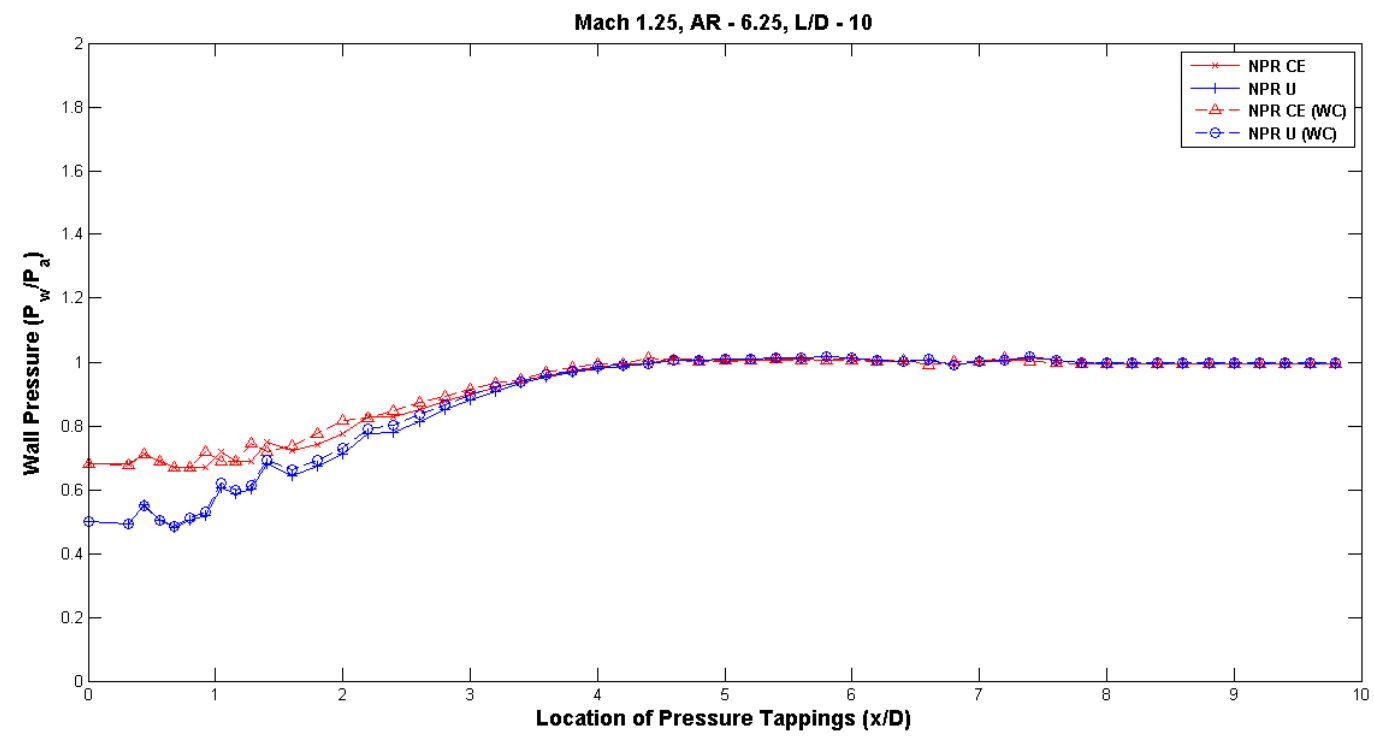

Figure 11. Wall Pressure $\left(\mathrm{P}_{\mathrm{w}} / \mathrm{P}_{\mathrm{a}}\right)$ (vs.) Location of Pressure Tapping (x/D) - Mach 1.25, AR $6.25, \mathrm{~L} / \mathrm{D}-10$

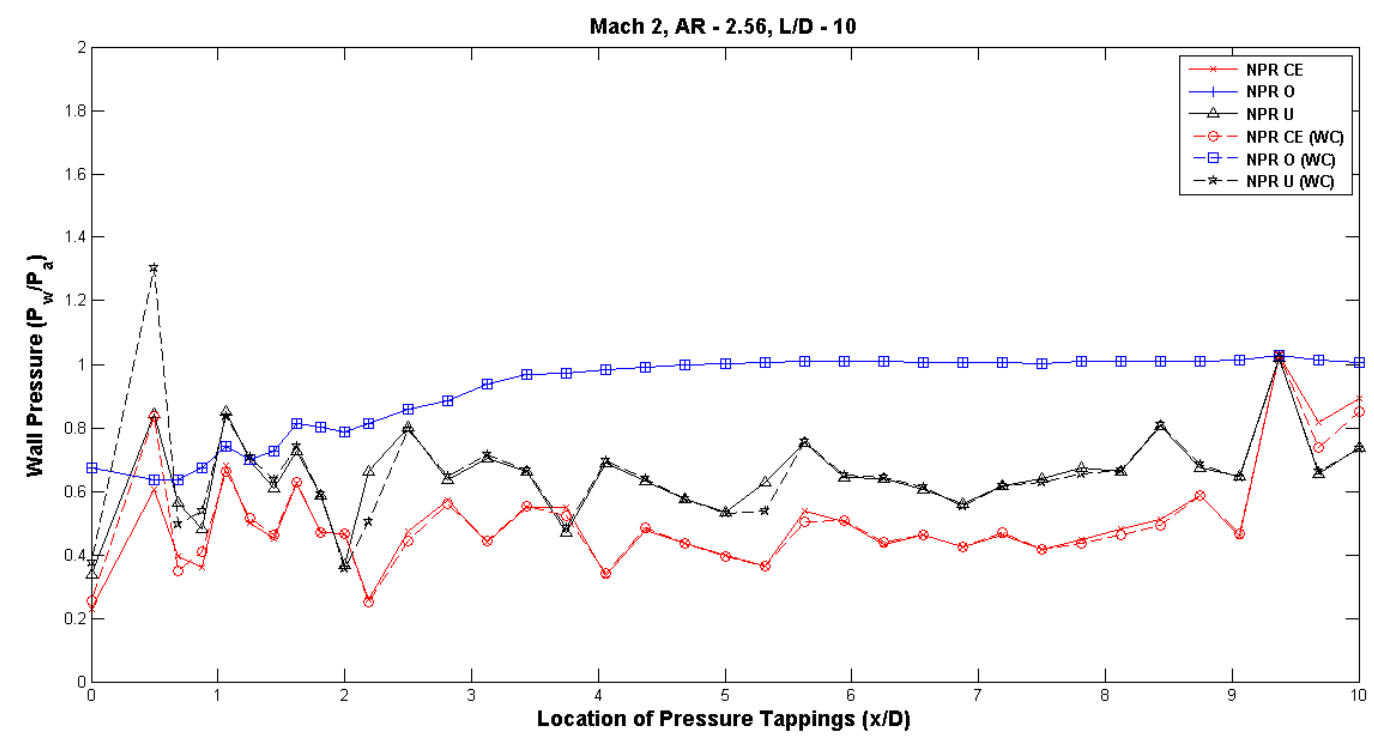

Figure 12. Wall Pressure $\left(\mathrm{P}_{\mathrm{w}} / \mathrm{P}_{\mathrm{a}}\right)$ (vs.) Location of Pressure Tapping $(\mathrm{x} / \mathrm{D})-$ Mach $2, \mathrm{AR}-2.56$, L/D - 10 
Figures 12 to 15 present the wall pressure field for all the four area ratios of the present study for Mach 2 and L/D = 10. Figures 12 and 13 show the flow development in the enlarged duct the lower area ratio and their trends are on the similar line for correctly expanded and under expanded cases with the exception that the flow field for the lower area ratio is wavy in nature as the relief available to the flow is the least and when the area ratio is increased this oscillatory nature is suppressed. When the nozzle is over expanded there is an oblique shock at the nozzle lip which results in increased value of wall pressure and in the downstream there is a gradual increase in the wall pressure within $\mathrm{x} / \mathrm{D}=3$.

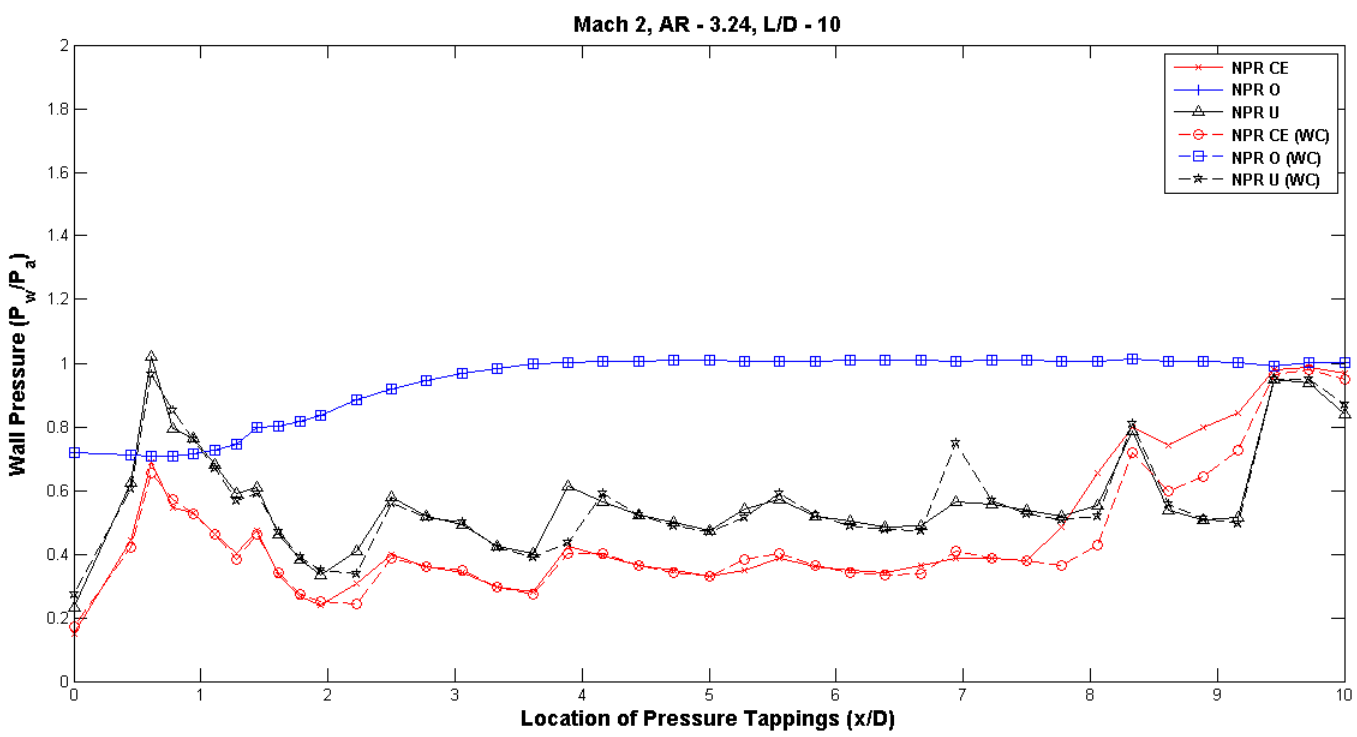

Figure 13. Wall Pressure $\left(\mathrm{P}_{\mathrm{w}} / \mathrm{P}_{\mathrm{a}}\right)$ (vs.) Location of Pressure Tapping (x/D) - Mach 2, AR - 3.24, $\mathrm{L} / \mathrm{D}-10$

Figures 14 and 15 show the flow development for the area ratios 4.84 and 6.25 at Mach 2 for $L / D=10$. Due to increase in the Mach number from 1.25 to 2, the effect area ratio which was visible at lower supersonic Mach number is not visible, the reason for this trend is that with increase in Mach number the wall pressure will increase and the effect of inertia on the flow field is dominant and the effect of area ratio has vanished. When jets are over expanded the initial value of the wall pressure is high and with marginal variation it attains $\mathrm{P}_{\mathrm{w}} / \mathrm{P}_{\mathrm{a}}=1$ for both the area ratios. When we analyze the results for correctly expanded case there is single jump in the wall pressure value and then smooth recovery of the wall pressure and control results in increasing the wall pressure up to $\mathrm{x} / \mathrm{D}=4.5$ for area ratio 4.84, whereas for area ratio 6.25 control results in decrease of wall pressure and smoothening of wall pressure. For under expanded case the oscillatory nature of the flow field is seen for both area ratios, however, for area ratio 6.25 the oscillations have been suppressed marginally. 


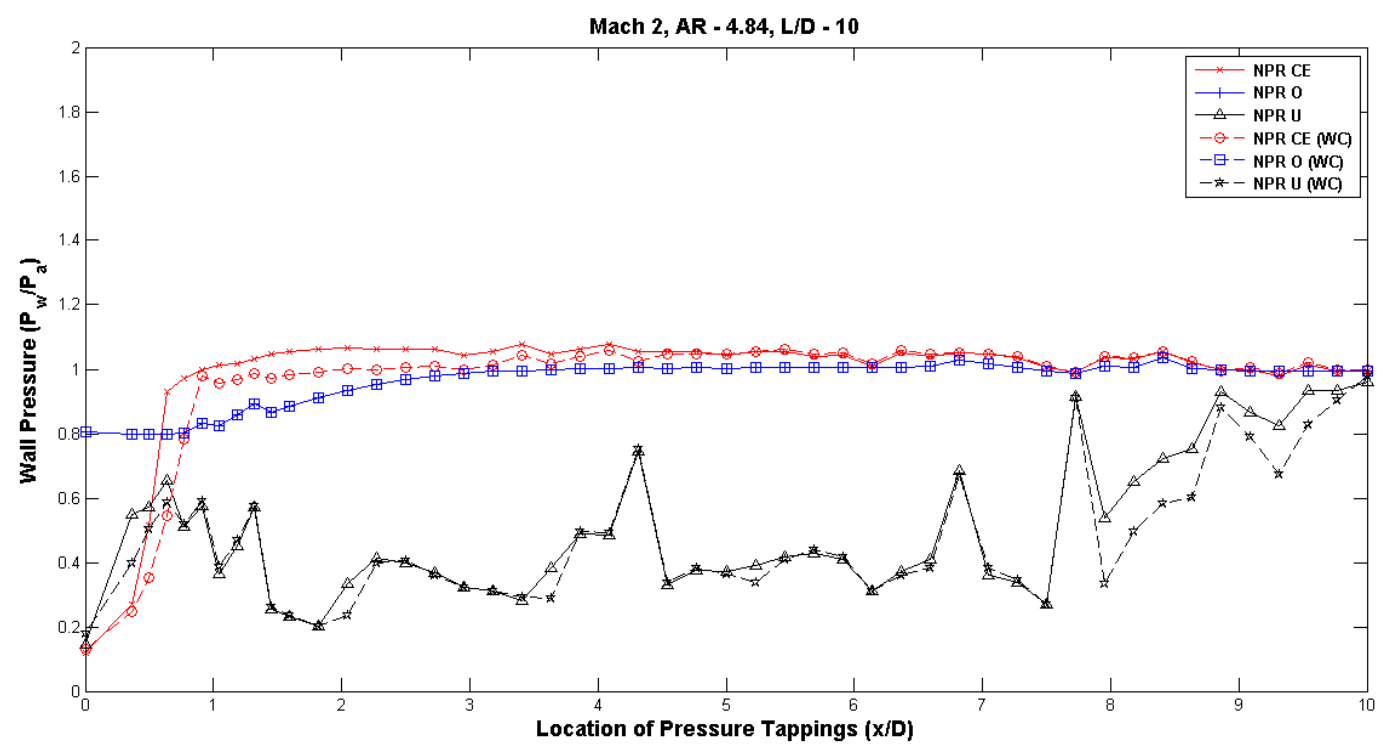

Figure 14. Wall Pressure $\left(\mathrm{P}_{\mathrm{w}} / \mathrm{P}_{\mathrm{a}}\right)$ (vs.) Location of Pressure Tapping (x/D) - Mach 2, AR - 4.84, L/D - 10

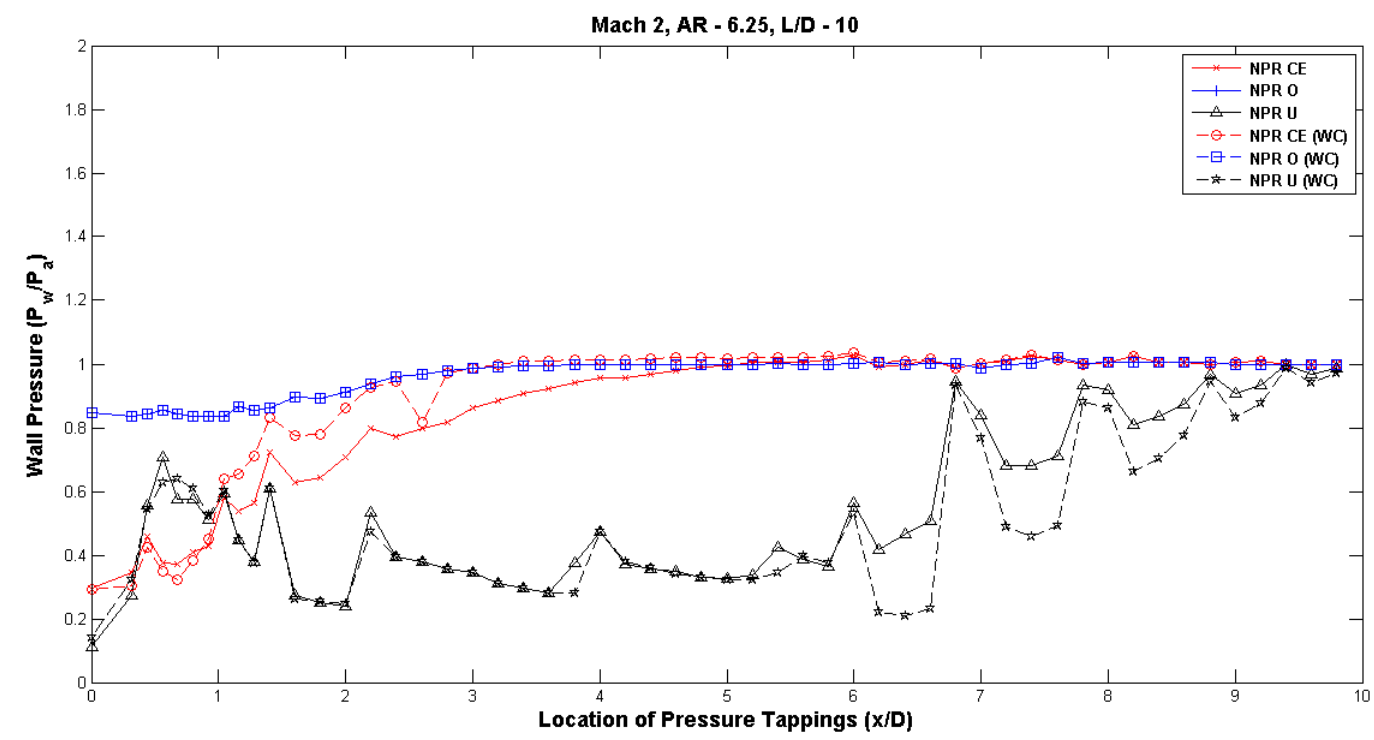

Figure 15. Wall Pressure $\left(\mathrm{P}_{\mathrm{w}} / \mathrm{P}_{\mathrm{a}}\right)$ (vs.) Location of Pressure Tapping $(\mathrm{x} / \mathrm{D})-$ Mach 2, $\mathrm{AR}-6.25$, L/D - 10

\section{Conclusion}

Micro-jets, have no effect in controlling base pressure for low supersonic flow conditions at varying area ratios (AR). In the case of correct expansion (CE) 
for Mach 1.25, the suction occurring at the base region gradually reduces with increase in area ratio, which enables the base pressure value to gradually increase. It is seen that there is very little effect of micro-jets in the under-expanded state for lower area ratios of 2.56 and 3.24 and no effect at all for higher area ratios.

Micro-jets, which are positioned close to the exit of the nozzle, try to decrease the suction occurring at the base region in under-expansion condition for Mach 1.25. This leads to increase in base pressure. With increase in area ratio, percentage increase in base pressure gradually reduces. For higher area ratios such as 4.84 and 6.25 the base pressure values seem to overlap each other for cases with and without micro-jet as control, which may emphasize the fact that for higher area ratios the effect of control mechanism diminishes.

The values for under-expansion are reasonably lower compared to the case of $\mathrm{CE}$. The pressure at the exit is higher than the ambient and hence could result in lower recirculation at the base, leading to lower base pressure values. It is interesting to note that as Mach number increases from 1.25 to 2, at $\mathrm{CE}$ there is a drop in base pressure values with or without control mechanism up to AR 4.84 and then there is a sudden rise in value in the case of AR 6.25. Similar to the case of Mach 1.25, for Mach 2, micro-jets have a better stand in enhancing base pressure for ARs 2.56 and 3.24 under correct expansion, while the controllability reduces with further increase in AR.

The effect of micro-jets is very negligible in the case of over-expansion, as the pressure after the nozzle exit is much less than the ambient pressure, leading to very low suction at the base and hence enabling the base pressure value to rise with increase in AR. In contrast, there is a sharp decline in base pressure with increase in area ratio in the case of under-expansion and micro-jets prove to be effective specifically for the under-expanded cases alone.

The control effectiveness will be at its best, wherever there is a favourable pressure gradient and in this study, it favours the under-expanded cases for both Mach numbers. The distinction is that the micro-jets play an active role in supersonic flow conditions such as Mach 2, as compared to low Mach numbers such as Mach 1.25. It could therefore be concluded that micro-jets are of use in boosting base pressure only at higher Mach numbers with larger area ratios at under-expanded conditions, as supported by quantitative data. 


\section{References}

Baig, Maughal Ahmed Ali, Al-Mufadi, Fahad, Khan, Sher Afghan and Rathakrishnan, E. (2011). Control of base flows with Micro-jets, Journal of Turbo and Jet Engines, Vol. 28, 59-69.

doi: $10.1515 / \mathrm{tjj} .2011 .009$

Chidambaranathan, Manisankar, Rathakrishnan, E., Verma, S.B. (2017). Control of Incident Shock Induced Separation at Mach 3.5 using an Array of Steady Micro-Jet Actuators. 7th European Conference for Aeronautics and Space Sciences (EUCASS)

doi: 10.13009/EUCASS2017-114

Eaton, J. K. and Johnston, J. P. (1981). A Review of Research on Subsonic Turbulent Flow Reattachment. AIAA Journal, vol. 19, pp. 1093-1100, doi: $10.2514 / 3.60048$

Khan, Sher Afghan and Rathakrishnan, E. (2002). Active control of suddenly expanded flows from over-expanded nozzles. Journal of Turbo and Jet Engines, Vol. 19, No. 1-2, 119-126.

doi: 10.1515/TJJ.2002.19.1-2.119

Khan, Sher Afghan. and Rathakrishnan, E. (2003). Control of suddenly expanded flows with Micro-jets. Journal of Turbo and Jet Engines, Vol. 20, No. 1, 6381.

doi: 10.1515/TJJ.2003.20.1.63

Khan, Sher Afghan. and Rathakrishnan, E. (2004). Active control of suddenly expanded flows from under expanded nozzles. Journal of Turbo and Jet Engines, Vol. 21, No. 4, 233-253

doi: 10.1515/TJJ.2004.21.4.233

Khan, Sher Afghan. and Rathakrishnan, E. (2006). Control of Suddenly Expanded Flow. Journal of Aircraft Engineering and Aerospace Technology, Vol. 78, No. 4, 293-309 doi: $10.1108 / 17488840610675573$

Korst, H.H. (1954). Comments on the effect of boundary layer on sonic flow through an abrupt cross-sectional area change. Journal of the Aeronautical Sciences, Vol. 21, 568-569. 
Sethuraman, Vigneshvaran. and Khan, Sher Afghan. (2016). Effect of sudden expansion for varied area ratios at subsonic and sonic flow regimes. International Journal of Energy, Environment and Economics, Vol. 24 Issue 1, 99-111.

Timofeev, I., V Aniskin, V., Maslov, A. (2017). Experimental study of shock-wave structure of supersonic under expanded Micro-jets. IOP Conf. Series: Journal of Physics: Conf. Series 899 (2017) 022018.

doi: 10.1088/1742-6596/899/2/022018

Wick, Robert S. (1953). The effect of boundary layer on sonic flow through an abrupt cross-sectional area change. Journal of the Aeronautical Sciences, Vol. 20, No. 10, 675-682.

Wick, Robert S. (1955). Further comments on the effect of boundary layer on sonic flow through an abrupt cross-sectional area change. Journal of the Aeronautical Sciences, Vol. 22, 135-137.

Williams, T.J., and Anderson, J.S. (1968). Base pressure and noise produced by the abrupt expansion of air in a cylindrical duct. Journal of Mechanical Engineering Science, Vol. 10, 262-268. 


\section{Appendix}

\section{Uncertainty Estimation}

The general procedure for estimating the uncertainties in the calculated quantities using measured data is described below. The derived general expression has been employed to demonstrate the estimation of uncertainties associated with base pressure and wall pressure calculated using the measured values of total pressure, base pressure, wall pressure and the ambient pressure. Let $x_{1}, x_{2}, x_{3}, \ldots \ldots \ldots, x_{i}, \ldots, x_{n}$ be the independent variables in the experimental measurement, and $u_{1}, u_{2}, u_{3}, \ldots \ldots, u_{i}, \ldots, u_{n}$ be the relative uncertainties of $x_{1}, x_{2}, x_{3}, \ldots \ldots \ldots, x_{i}, \ldots, x_{n}$. Let $R$ be the experimental result calculated from the measured data.

The first step in the procedure is to analyze how errors in the $x_{i}$ propagate into the calculation of $R$ from the measured values. The quantity $R$ can be expressed as,

$$
R=R\left(x_{1}, x_{2}, x_{3}, \ldots \ldots \ldots, x_{i}, \ldots, x_{n}\right)
$$

The effect of error in measuring individual $x_{i}$ on $\mathrm{R}$ may be estimated by analogy to derivative of a function. A variation $\delta x_{i}$ in $x_{i}$ would cause $\mathrm{R}$ to vary according to,

$$
\delta R_{i}=\frac{\partial R}{\partial x_{i}} \delta x_{i}
$$

For applications, it is convenient to normalize the above equation by dividing throughout by $\mathrm{R}$ to obtain,

$$
\frac{\delta R_{i}}{R}=\frac{1}{R} \frac{\partial R}{\partial x_{i}} \delta x_{i}=\frac{x_{i}}{R} \frac{\partial R}{\partial x_{i}} \frac{\delta x_{i}}{x_{i}}
$$

Equation (3) might be used to estimate the uncertainty interval $\left(u_{R_{i}}\right)$ in the result $R$, due to variation in $x_{i}$. To do this, substitute the uncertainty interval for $x_{i}$, as

$$
u_{R_{i}}=\frac{x_{i}}{R} \frac{\partial R}{\partial x_{i}} u_{x_{i}}
$$


Uncertainty in $R$ due to the combined effect of uncertainty intervals in $\mathrm{x}_{\mathrm{i}}$ may be obtained by considering, (i) the random error in each variable as a range of values within the uncertainty interval; (ii) the fact that it is unlikely that all errors will add to the uncertainty at the same time; (iii) it can be shown that the best representation for the uncertainty interval of the result is,

$$
u_{R}= \pm\left[\left(\frac{x_{1}}{R} \frac{\partial R}{\partial x_{1}} u_{1}\right)^{2}+\left(\frac{x_{2}}{R} \frac{\partial R}{\partial x_{2}} u_{2}\right)^{2}+\cdots+\left(\frac{x_{n}}{R} \frac{\partial R}{\partial x_{n}} u_{n}\right)^{2}\right]^{1 / 2}
$$

This equation is the general expression for estimating the uncertainties in any calculated value from measured data. However, this expression has to be cast in the appropriate form before using it to estimate the uncertainty.

\section{Uncertainty in Base Pressure}

In this section, a procedure to estimate in uncertainty in base pressure $\mathrm{P}_{\mathrm{b}}$ is discussed. The measured base pressure $\mathrm{P}_{\mathrm{b}}$ depends on the nozzle pressure ratio (NPR), $\mathrm{P}_{0} / \mathrm{P}_{\mathrm{a}}$, control pressure, $\mathrm{P}_{\mathrm{c}}$ and atmospheric pressure $\mathrm{P}_{\mathrm{a}}$. Thus,

$$
P_{b}=P_{b}\left(P_{0}, P_{c}, P_{a}\right)
$$

With Equation (5), the uncertainty in base pressure can be expressed as,

$$
u_{P_{b}}=\left[\left(\frac{P_{o}}{P_{b}} \frac{\partial P_{b}}{\partial P_{0}} u_{P_{0}}\right)^{2}+\left(\frac{P_{c}}{P_{b}} \frac{\partial P_{b}}{\partial P_{c}} u_{P_{c}}\right)^{2}+\left(\frac{P_{a}}{P_{b}} \frac{\partial P_{b}}{\partial P_{a}} u_{P_{a}}\right)^{2}\right]^{1 / 2}
$$

\section{Sample Calculation}

Uncertainty in base pressure is calculated for NPR 11, Mach 2.0 and area ratio 6.25. Atmospheric pressure $=741 \mathrm{~mm}$ of $\mathrm{Hg}=0.741 \mathrm{~m}$ of $\mathrm{Hg}$. At NPR 11 stagnation pressure in the settling chamber and in the control chamber are $7.41 \mathrm{~m}$ of $\mathrm{Hg}$ (gauge) and $7.05 \mathrm{~m}$ of $\mathrm{Hg}$ (gauge). Base pressure $=-0.63907 \mathrm{~m}$ of $\mathrm{Hg}$ (gauge). Assuming one $0.0254 \mathrm{~m}$ of $\mathrm{Hg}$ as the maximum possible error in the measurement of stagnation pressure in settling chamber, control chamber and base pressure. In Equation (7) the three groups of terms on the right-hand side are, 


$$
\begin{gathered}
\frac{P_{0}}{P_{b}} \frac{\partial P_{b}}{\partial P_{0}} u_{P_{0}}=\left(\frac{7.41}{0.10193}\right)(0.036)(0.0034)=0.00897 \\
\frac{P_{c}}{P_{b}} \frac{\partial P_{b}}{\partial P_{c}} u_{P_{c}}=\left(\frac{7.05}{0.10193}\right)(0.0651)(0.0036)=0.01494 \\
\frac{P_{a}}{P_{b}} \frac{\partial P_{b}}{\partial P_{a}} u_{P_{a}}=\left(\frac{0.741}{0.10193}\right)(0.069)(0.00342)=0.00172 \\
u_{P_{b}}= \pm\left[(0.00897)^{2}+(0.01494)^{2}+(0.00172)^{2}\right]^{1 / 2}= \pm 1.75 \%
\end{gathered}
$$

